
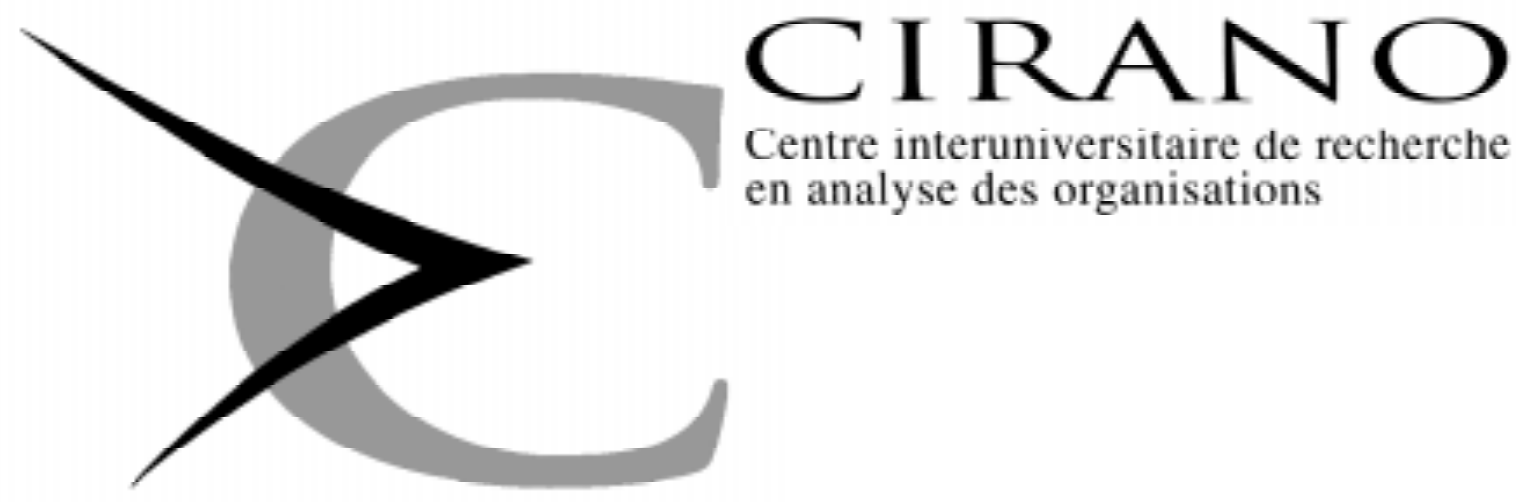

Centre interuniversitaire de recherche en analyse des organisations

Série Scientifique

Scientific Series

$95 \mathrm{~s}-43$

\title{
Empirical Martingale \\ Simulation for Asset Prices
}

Jin-Chuan Duan, Jean Guy Simonato 


\section{CIRANO}

Le CIRANO est une corporation privée à but non lucratif constituée en vertu de la Loi des compagnies du Québec. Le financement de son infrastructure et de ses activités de recherche provient des cotisations de ses organisations-membres, d'une subvention d'infrastructure du ministère de l'Industrie, du Commerce, de la Science et de la Technologie, de même que des subventions et mandats obtenus par ses équipes de recherche. La Série Scientifique est la réalisation d'une des missions que s'est données le CIRANO, soit de développer l'analyse scientifique des organisations et des comportements stratégiques.

CIRANO is a private non-profit organization incorporated under the Québec Companies Act. Its infrastructure and research activities are funded through fees paid by member organizations, an infrastructure grant from the Ministère de l'Industrie, du Commerce, de la Science et de la Technologie, and grants and research mandates obtained by its research teams. The Scientific Series fulfils one of the missions of CIRANO: to develop the scientific analysis of organizations and strategic behaviour.

\section{Les organisations-partenaires / The Partner Organizations}

-Ministère de l'Industrie, du Commerce, de la Science et de la Technologie.

-École des Hautes Études Commerciales.

-École Polytechnique.

-Université de Montréal.

-Université Laval.

-McGill University.

-Université du Québec à Montréal.

-Bell Québec.

-La Caisse de dépôt et de placement du Québec.

-Hydro-Québec.

-Fédération des caisses populaires de Montréal et de l'Ouest-du-Québec.

-Téléglobe Canada.

-Société d'électrolyse et de chimie Alcan Ltée.

-Avenor.

-Service de développement économique de la ville de Montréal.

-Raymond, Chabot, Martin, Paré

Ce document est publié dans l'intention de rendre accessibles les résultats préliminaires de la recherche effectuée au CIRANO, afin de susciter des échanges et des suggestions. Les idées et les opinions émises sont sous l'unique responsabilité des auteurs, et ne représentent pas nécessairement les positions du CIRANO ou de ses partenaires.

This paper presents preliminary research carried out at CIRANO and aims to encourage discussion and comment. The observations and viewpoints expressed are the sole responsibility of the authors. They do not necessarily represent positions of CIRANO or its partners.

\section{ISSN 1198-8177}




\title{
Empirical Martingale Simulation for Asset Prices ${ }^{\star}$
}

\author{
Jin-Chuan Duan ${ }^{\dagger}$, Jean Guy Simonato
}

\begin{abstract}
Résumé / Abstract
Cette étude propose une modification simple aux procédures traditionnelles de calcul de prix des produits dérivés par simulation de Monte Carlo. La modification impose la propriété de martingale aux trajectoires simulées de la variable d'état sous-jacente. L'utilisation de cette procédure assure que l'estimé de prix respecte les bornes rationnelles d'option tout en diminuant de façon substantielle la variance des estimés de prix. La procédure peut aisément être jumelée aux méthodes traditionnelles de réduction de variance afin d'obtenir une plus grande efficacité. Une étude de simulation est présentée pour des options d'achat Européennes et Asiatiques. Les résultats indiquent que la méthode obtient des réductions substantielle de la variance des estimés de prix et ce, particulièrement pour les options «in» et «at the money».

This paper proposes a simple modification to the standard Monte Carlo simulation procedure for computing the prices of derivative securities. The modification imposes the martingale property on the simulated sample paths of the underlying asset price. This procedure is referred to as the empirical martingale simulation (EMS). The EMS ensures that the price estimated by simulation satisfies rational option pricing bounds. The EMS also yields a substantial error reduction for the price estimate. The EMS can be easily coupled with the standard variance reduction methods to obtain greater computational efficiency. Simulation studies are conducted for European and Asian call options using both the Black and Scholes and GARCH option pricing frameworks. The results indicate that the EMS yields substantial variance reduction particularly for in- and at-the-money options.
\end{abstract}

Mots clé : Martingale, Evaluation des Options, Simulation de Monte Carlo, GARCH, Options Asiatiques

Keywords : Martingale, Option Pricing, Monte Carlo Simulation, GARCH, Asian Options

\footnotetext{
* This research is supported by SSHRC of Canada, grant \# 410-95-0734. We thank Phelim Boyle for his valuable comments. Correspondence to : J.C. Duan, Faculty of Management, McGill University, 1001 Sherbrooke Street West, Montréal, Canada H3A 1G5; Tel: (514) 398-3876; E-mail: Duan@Management.McGill.CA.

${ }^{\dagger}$ McGill University and CIRANO

* Université du Québec à Montréal et CIRANO
} 


\section{Introduction}

Monte Carlo simulation is a widely used tool for estimating derivative security prices when there is no closed-form solution. It was first introduced by Boyle (1977) to option pricing. Monte Carlo method is especially useful when one deals with path dependent asset prices and/or option payoffs; for example, it has been used in Duan (1995) to compute the GARCH option prices (path dependent asset prices) and in Kemna and Vorst (1990) to compute Asian option prices (path dependent payoffs). Boyle, et al (1995) provides a comprehensive survey on the recent developments in Monte Carlo methods for option pricing.

The price of a derivative contract in an arbitrage-free economy can be expressed as a discounted average of its random payoffs. Monte Carlo simulation is hence a natural tool for computing this average. The commonly used Monte Carlo simulation procedure for option pricing can be briefly described as follows: first simulate sample paths for the underlying asset price; second compute its corresponding option payoff for each sample path; and finally average the simulated payoffs and discount the average to yield the Monte Carlo price of an option. Although arbitrary degree of accuracy can in principle be achieved, Monte Carlo simulation tends to be a rather numerically intensive method if a high degree of accuracy is desired. This is, of course, due to the well-known fact that the standard error of a Monte Carlo estimate is inversely proportional to the square root of the number of simulated sample paths. A less known difficulty related to the use of Monte Carlo simulation is the occurrence of the simulated price violating rational option pricing bounds, and hence being a non-sensible price estimate. This bound violation could have serious implications. The implied volatility based on the Black and Scholes (1973) formula is often used as a standardized measure for examining more complex option pricing models; for example, Hull and White (1987) and Duan (1995). When the option pricing bound is violated, the Black-Scholes implied volatility cannot even be computed.

The idea of this paper is based on a simple observation that simulated sample paths for the underlying asset price almost always fail to possess the martingale property even though the theoretical model does. This results from the fact that simulation can only approximate the theoretical properties because of finite repetitions and the quality of the random number generator. The failure to ensure the martingale property has particularly serious consequences because the asset price dynamic is typically modeled as an exponential (semi-)martingale. This multiplicative system has a rather undesirable error propagation property. It often requires a very large number of simulation repetitions to dampen simulation errors. We propose a simple correction to the standard procedure by ensuring that the simulated sample paths are together a martingale in an "empirical" sense. This correction will be referred to as empirical martingale simulation (EMS). With the EMS one can be certain that option pricing bounds, due to Jensen's inequality, are satisfied in simulation. Apart from yielding more sensible price estimates, the use of the EMS can substantially reduce Monte Carlo errors, particularly significant for in- and at-the-money options. The error reduction is irrespective of the number of sample paths, and is obtained for the plain-vanilla European options as well as for the path-dependent ones such as Asian options. The results also hold true for both 
the Black-Scholes and GARCH option pricing frameworks.

The EMS can also be coupled with the standard variance reduction techniques. A number of such techniques are available for option pricing. Antithetic and control-variate simulations are perhaps the most widely known procedures. We show in this paper that the EMS can be easily incorporated into these variance reduction techniques to obtain even greater simulation efficiency. The EMS correction is truly simple and practically requires no additional programming efforts.

\section{The Martingale Property in Monte Carlo Simulation}

The theoretical works for contingent claim pricing mostly rely on absence of arbitrage. In Black and Scholes (1973) and Merton (1973), option pricing formulas were derived from this principle. The martingale connection to the arbitrage-free price system was first observed by Cox and Ross (1976) and later formalized by Harrison and Kreps (1979) and Harrison and Pliska (1981). In an explicit equilibrium setting such as Lucas (1978), the martingale connection can also be established; for example, Duan (1995) used this approach to derive the GARCH option pricing model. In this paper we explore the martingale property in Monte Carlo simulation. For the ease of exposition, we consider a price system consisting of two securities - one risky and one risk-free. The risky security, say a common stock, does not pay dividends, and its price, denoted by $S_{t}$, has the following dynamic under the risk neutral probability measure $Q$ :

$$
S_{t}=S_{0} \exp \left[r t-\frac{1}{2} \int_{0}^{t} \sigma_{s}^{2} d s+\int_{0}^{t} \sigma_{s} d W_{s}\right]
$$

where $r$ is the continuously compounded return on the risk-free security, $\sigma_{s}$ is the instantaneous standard deviation of the asset return and $W_{s}$ is a standard Brownian motion under probability measure $Q .{ }^{1}$ It is easy to verify that the discounted asset price is indeed a $Q$-martingale; that is, for any $t \geq \tau \geq 0$,

$$
E^{Q}\left[e^{-r t} S_{t} \mid \mathcal{F}_{\tau}\right]=e^{-r \tau} S_{\tau}
$$

where $E^{Q}(\cdot)$ denotes the expectation operator under the risk neutral measure $Q$ and $\mathcal{F}_{\tau}$ the information filtration up to time $\tau$.

In a typical Monte Carlo simulation, this martingale property almost always fails in the simulated sample. In other words, the discounted average of $S_{t}$ computed from a Monte Carlo simulation will be in almost all cases different from $S_{\mathbf{0}}$. This discrepancy between the "empirical" and theoretical values will, of course, depend on the sample size and the quality of the random number generator. However, even a small departure of the sample value from its theoretical one can have important consequences. For example, in the case of a European call option, the failure to "empirically" satisfy the martingale property may result in a violation of the following rational option pricing bound:

$$
C_{0}(t)>\max \left(S_{0}-K e^{-r t}, 0\right),
$$

where $K$ is the exercise price and $C_{0}(t)$ is the current price of the European call option maturing at time $t^{2}$ This bound can be derived from a direct application of Jensen's inequality to the

\footnotetext{
${ }^{1}$ For option pricing in the GARCH framework, a discrete-time analogous formula can be found in Duan (1995).

${ }^{2}$ The failure to "empirically" possess the martingale property can also lead to the violation of the put-call parity.
} 
theoretical expression:

$$
C_{\mathbf{0}}(t)=e^{-r t} E^{Q}\left[\max \left(S_{t}-K, 0\right) \mid \mathcal{F}_{\mathbf{0}}\right] .
$$

The sample equivalent to the RHS of (4) may be less than the right-hand side (RHS) of (3) if the discounted average of $S_{t}$ is smaller than $S_{\mathbf{0}}$.

This point can be better understood by considering a deep in-the-money call. Since the "max" function causes very few truncations at zero, the theoretical call price is well approximated by:

$$
C_{0}(t) \approx e^{-r t}\left[E^{Q}\left(S_{t} \mid \mathcal{F}_{\mathbf{0}}\right)-K\right] \text { if } K / S_{\mathbf{0}} \text { is small. }
$$

Define the discounted average of the simulated asset prices at time $t$ with $n$ sample paths as:

$$
\hat{S}_{\mathbf{0}}(t, n)=\frac{1}{n} e^{-r t} \sum_{i=1}^{n} \hat{S}_{i}(t),
$$

where $\hat{S}_{i}(t)$ is the $i$ th simulated asset price at time $t$, for $i=1, \ldots, n$. The corresponding call price by Monte Carlo simulation, denoted by $\hat{C}_{0}(t, n)$, must be well approximated by:

$$
\begin{aligned}
\hat{C}_{0}(t, n) & =\frac{1}{n} e^{-r t} \sum_{i=1}^{n} \max \left[\hat{S}_{i}(t)-K, 0\right] \\
& \approx \hat{S}_{\mathbf{0}}(t, n)-K e^{-r t} \text { if } K / S_{\mathbf{0}} \text { is small. }
\end{aligned}
$$

If $\hat{S}_{\mathbf{0}}(t, n)$ is smaller than $S_{\mathbf{0}}$, it is possible that the computed call price violates the rational option pricing bound; that is, $\hat{C}_{\mathbf{0}}(t, n) \leq \max \left(S_{0}-K e^{-r t}, 0\right)$.

To illustrate this bound violation, we perform a simulation study using the Black and Scholes (1973) model. For this model, the asset price process is a special case of (1) with a constant volatility. The Monte Carlo option price for a given $n$ and $t$ can be computed according to (7). The numbers in Table 1 are the percentages of bound violation in 1000 Monte Carlo repetitions. The first column of the table indicates the asset-to-strike price ratio. Three maturities $-1,3$ and 9 months - are considered. We also conduct the analysis using 1000 and 10,000 sample paths in each of the Monte Carlo calculations.

The percentage of bound violations is higher for deep in- and out-of-the-money options. This percentage can attain $50 \%$ for deep in-the-money and $100 \%$ for deep out-of-the-money. The bound violation lessens when the number of sample paths increases. The occurrence of bound violation also depends on the maturity of an option. For shorter-maturity options, it is more likely to experience a bound violation even with 10,000 sample paths. These results are expected because the price of an option approaches the pricing bound when the strike price is either increased or decreased. In other words, the time-value component of an option decreases when the strike price is pushed to the extremes. When the time-value component drops in magnitude, a small Monte Carlo error can cause a bound violation. The time-value component argument also works in the dimension of option maturity and the number of sample paths. Increasing an option's maturity yields a higher time-value component, and hence causes less violations. An increase in the number of sample paths reduces Monte Carlo errors so that a given time-value component is more likely to be sufficient for covering Monte Carlo errors. 


\section{The Empirical Martingale Simulation}

In this section we present a simple correction to the standard Monte Carlo simulation procedure. This proposed correction imposes the martingale property on the collection of the simulated sample paths. This new simulation procedure, referred to as the empirical martingale simulation (EMS), generates the EMS asset prices at a sequence of time points, $t_{1}, t_{2}, \cdots, t_{m}$, using the following dynamic:

$$
S_{i}^{*}\left(t_{j}, n\right)=S_{0} \frac{Z_{i}\left(t_{j}, n\right)}{Z_{0}\left(t_{j}, n\right)}
$$

where

$$
\begin{aligned}
& Z_{i}\left(t_{j}, n\right)=S_{i}^{*}\left(t_{j-1}, n\right) \frac{\hat{S}_{i}\left(t_{j}\right)}{\hat{S}_{i}\left(t_{j-1}\right)} \\
& Z_{0}\left(t_{j}, n\right)=\frac{1}{n} e^{-r t_{j}} \sum_{i=1}^{n} Z_{i}\left(t_{j}, n\right) .
\end{aligned}
$$

Note that $\hat{S}_{i}(t)$ is the $i$ th simulated asset price at time $t$ prior to the EMS adjustment. The adjustment steps can be understood as follows. First, we take the standard simulated return from $t_{j-1}$ to $t_{j}$, i.e., $\hat{S}_{i}\left(t_{j}\right) / \hat{S}_{i}\left(t_{j-1}\right)$, to create a temporary asset price at time $t_{j}$, i.e., $Z_{i}\left(t_{j}, n\right)$. Second, we compute the discounted sample average, $Z_{0}\left(t_{j}, n\right)$. Finally, we compute the EMS asset price at time $t_{j}$ by (9). After the EMS correction, the simulation moves on to the next time point, and repeats the whole process again. Note that the EMS conducts a simulation of $n$ sample points at one time, which is required for making the EMS correction. If the use of a very large $n$ causes a memory allocation problem, the sample can be broken into subsamples with each undergoing the EMS correction separately.

The EMS bears some resemblance to the moment-matching method of Barraquand (1994). ${ }^{3}$ The EMS is, however, entirely different from the moment-matching method in the following sense. For the EMS, the correct first moment in simulation is ensured by using a multiplicative adjustor instead of using an additive one as in the moment-matching method when it is applied to the asset price directly. This difference is extremely important because asset prices are typically modeled as exponential (semi-)martingales. The multiplicative adjustment ensures no domain violation whereas the additive adjustment cannot. ${ }^{4}$ If the moment-matching adjustment is applied to the exponent of an exponential martingale (logarithmic asset price), in which case there will be no domain violation, the simulated asset prices will no longer be an "empirical" martingale. The EMS correction is hence the most natural adjustment, and it is made to the entire simulated time series as required by the theoretical asset price dynamic.

\footnotetext{
${ }^{3}$ We use the terminology of Boyle, et al (1995) to refer to the quadratic resampling method of Barraquand (1994) as the moment-matching method.

${ }^{4}$ Footnote 7 in Boyle, et al (1995) provides a discussion on domain violation of Barraquand's (1994) momentmatching method.
} 
The discounted EMS asset price estimate at time 0 is therefore:

$$
\begin{aligned}
S_{\mathbf{0}}^{*}(t, n) & =\frac{1}{n} e^{-r t} \sum_{i=1}^{n} S_{i}^{*}(t, n) \\
& =S_{\mathbf{0}}
\end{aligned}
$$

This is true for any $n$ and $t \in\left\{t_{1}, t_{2}, \cdots, t_{m}\right\}$. Since the EMS asset price can be regarded as an "empirical" martingale with equal probabilities assigned to all simulated sample paths, the use of Jensen's inequality ensures that the option pricing bound is always satisfied. Formally, we define the EMS option price estimate as

$$
C_{0}^{*}(t, n)=\frac{1}{n} e^{-r t} \sum_{i=1}^{n} \max \left[S_{i}^{*}(t, n)-K, 0\right]
$$

It follows that $C_{0}^{*}(t, n)>\max \left[S_{0}^{*}(t, n)-K e^{-r t}, 0\right]=\max \left(S_{0}-K e^{-r t}, 0\right)$.

The EMS for derivatives pricing also preserves the consistency, i.e., the convergence to the theoretical value, under the fairly general conditions. This is a relevant because the EMS sample paths are by construction not independent. The following proposition provides a general characterization for the consistency.

Proposition 1. Let $S\left(t_{j}\right)$ satisfy the strong law of large numbers for all $t_{j}$ 's, i.e., $\hat{S}_{\mathbf{0}}\left(t_{j}, n\right) \rightarrow S_{\mathbf{0}}$ almost surely as $n \rightarrow \infty$. If the payoff function, $f\left[S\left(t_{1}\right), \cdots, S\left(t_{m}\right)\right]$, is uniformly continuous, then as $n \rightarrow \infty$,

$$
\frac{1}{n} \sum_{i=1}^{n}\left|f\left[S_{i}^{*}\left(t_{1}, n\right), \cdots, S_{i}^{*}\left(t_{m}, n\right)\right]-f\left[\hat{S}_{i}\left(t_{1}\right), \cdots, \hat{S}_{i}\left(t_{m}\right)\right]\right| \rightarrow 0, \text { almost surely. }
$$

Proof: See Appendix.

Proposition 1 states that for a well-behaved payoff function, the EMS is asymptotically equivalent to the standard Monte Carlo simulation. If the price estimate based on the standard Monte Carlo simulation is consistent, it must also be true for the EMS price estimate. For a European option, it is clear that the payoff function is uniformly continuous. The EMS price estimate is thus consistent irrespective of the pricing framework being the Black and Scholes or GARCH or anything else. For Asian options, the same conclusion applies. Proposition 1 is nevertheless limited; for example, digital (binary) options have discontinuous payoff functions. This type of contracts can be dealt with if we strengthen the distribution requirement. We need to have the following definition to proceed with the discussion.

Definition 1. A real-valued function mapping from a subset of $R^{m}$ to $R$ is said to satisfy the generic uniform continuity if there exists a finite collection of connected open subsets of the domain with their union being dense in the domain, and the function is uniformly continuous over any element of this finite collection. 
Proposition 2. Let $S\left(t_{j}\right)$ have a continuous distribution and satisfy the strong law of large numbers for all $t_{j}$ 's, i.e., $\hat{S}_{0}\left(t_{j}, n\right) \rightarrow S_{0}$ almost surely as $n \rightarrow \infty$. If the payoff function, $f\left[S\left(t_{1}\right), \cdots, S\left(t_{m}\right)\right]$, satisfy the generic uniform continuity, then as $n \rightarrow \infty$,

$$
\frac{1}{n} \sum_{i=1}^{n}\left|f\left[S_{i}^{*}\left(t_{1}, n\right), \cdots, S_{i}^{*}\left(t_{m}, n\right)\right]-f\left[\hat{S}_{i}\left(t_{1}\right), \cdots, \hat{S}_{i}\left(t_{m}\right)\right]\right| \rightarrow 0, \text { almost surely. }
$$

Proof: See Appendix.

The payoff function of a digital option takes on two values -0 and 1 . Although it is discontinuous, it satisfies the generic uniform continuity. Proposition 2 implies that if the underlying asset price has a continuous distribution, the EMS price estimates for its digital options must also be consistent. This in turn suggests that the EMS correction works well under the typical distribution assumption for option pricing. In fact, we can conclude from Proposition 2 that the EMS is applicable to almost all relevant cases of derivative pricing.

Another attractive feature of the EMS is its ability to reduce the Monte Carlo simulation error. The source of error reduction comes from the fact that the EMS ensures the martingale property in the simulated sample paths. Because the discounted average asset price, $S_{0}^{*}(t, n)$, always equals $S_{\mathbf{0}}, \operatorname{Var}\left[S_{\mathbf{0}}^{*}(t, n)\right]=0$. This is, however, not true for $\hat{S}_{\mathbf{0}}(t, n)$, i.e., $\operatorname{Var}\left[\hat{S}_{\mathbf{0}}(t, n)\right]>0$. The implication of this property for option prices is best seen for in-the-money options. The call price computed with a Monte Carlo simulation with and without the EMS correction can be written approximately as:

$$
\begin{aligned}
& \hat{C}_{\mathbf{0}}(t, n) \approx \hat{S}_{\mathbf{0}}(t, n)-K e^{-r t} \text { if } K / S_{\mathbf{0}} \text { is small, } \\
& C_{\mathbf{0}}^{*}(t, n) \approx S_{\mathbf{0}}^{*}(t, n)-K e^{-r t} \text { if } K / S_{\mathbf{0}} \text { is small. }
\end{aligned}
$$

This in turn implies that

$$
\begin{aligned}
\operatorname{Var}\left[\hat{C}_{\mathbf{0}}(t, n)\right] & \approx \operatorname{Var}\left[\hat{S}_{\mathbf{0}}(t, n)\right]>0 \text { if } K / S_{\mathbf{0}} \text { is small, } \\
\operatorname{Var}\left[C_{0}^{*}(t, n)\right] & \approx \operatorname{Var}\left[S_{\mathbf{0}}^{*}(t, n)\right]=0 \text { if } K / S_{\mathbf{0}} \text { is small. }
\end{aligned}
$$

The EMS option price estimate therefore has a smaller variance, or even negligible if the option is deep in-the-money. The numerical significance of the EMS error reduction is examined in the next section.

\section{The EMS Applications}

The application of the EMS to two option pricing frameworks - Black and Scholes (1973) and GARCH (Duan, 1995) - is studied here. For each pricing framework, we consider two types of contracts - European calls and Asian calls. We choose two pricing frameworks and two different types of option contracts to demonstrate path-dependency in terms of option payoffs and/or asset price dynamic. Asian options give an interesting case of path-dependent option payoffs that require Monte Carlo simulation, whereas the GARCH framework provides a situation in which asset price dynamic is path-dependent. 
For each model and contract, we generate 1000 Monte Carlo option price estimates. These prices are computed with both 1000 and 10,000 sample paths to examine the impact caused by different numbers of sample paths. ${ }^{5}$ We consider three maturities $-1,3$ and 9 months - and three asset-to-strike price ratios $-1.1,1$ and 0.9. In our numerical analyses, one year is assumed to have 365 days for the purpose of annualization. We compare the EMS with the standard Monte Carlo simulation. We also incorporate the variance reduction techniques such as antithetic and control-variate simulation whenever appropriate.

\subsection{The Black and Scholes option pricing framework}

For European call options in the Black and Scholes (1973) framework, the underlying asset price is simulated using (1) and setting $\sigma_{t}$ to a constant. This simulation need not be done step-by-step because it is not path dependent. ${ }^{6}$ For the EMS, we simply take the simulated random variates and apply once the EMS correction. The results are presented in Table 2.

For European calls, the mean value of either the crude Monte Carlo or the EMS prices in 1000 repetitions is very close to its theoretical price. As expected, for all cases presented in this table, the EMS option prices have smaller standard deviations when compared to the crude Monte Carlo simulation. The last row in each panel reports the ratios of the crude simulation to the EMS standard deviations. The reduction in variance is not sensitive to the number of sample paths. However, changes in this ratio are observed when the maturity and exercise price are varied. For the in-the-money short-maturity option, the ratio reveals a phenomenal error reduction. The standard deviation of the EMS price is smaller by a factor of approximately 10 . The decrease in standard deviation is very substantial for at-the-money short-maturity options with a factor of approximately 2 . When the maturity of the option is increased, the error reduction for in-the-money options becomes smaller, but still substantial. This can be explained by a larger probability for the asset price to finish out-of-the-money when the maturity is increased. In short, whenever there is a larger number of truncations caused by the "max" function, the EMS has a smaller efficiency gain. For out-of-the-money options, however, the ratio of standard deviations increases as the maturity increases. This can be explained by the relative increase in the standard deviations of the crude Monte Carlo simulation and the EMS. When the maturity is increased, the standard deviation of the EMS increases at a slower rate than that of the crude Monte Carlo simulation. The increase in maturity therefore has an effect of levelling the error reduction across moneyness positions. The efficiency gain of the EMS is nevertheless significant across the board.

For Asian call options, the entire sample path of the asset price becomes important because the option payoff is based on the path average of the asset prices. We assume that the path average is calculated on daily closing prices. The asset prices must then be simulated daily according to

$$
S_{t+1}=S_{t} \exp \left[r-\frac{\sigma^{2}}{2}+\sigma \varepsilon_{t+1}\right]
$$

\footnotetext{
${ }^{5}$ We use the built-in normal random number generator of the matrix programming language GAUSS version 3.2.12.

${ }^{6}$ For European options, a closed-form solution exists. We only use these options as a means to compare the EMS with the standard simulation procedure.
} 
where $r$ and $\sigma$ are the daily risk-free rate and instantaneous standard deviation, respectively. The random variable $\varepsilon_{t+1}$ is an element of an i.i.d. standard normal random sequence. Let the maturity of the Asian call option be $T$, for the $i$ th sample path, its payoff equals max $\left(\hat{A}_{i, T}-K, 0\right)$ where $\hat{A}_{i, T}=\frac{1}{T} \sum_{t=1}^{T} \hat{S}_{i}(t)$. The $i$ th sample path for the EMS is obtained using the correction to $\hat{S}_{i}(t)$ described in (9) period-by-period to the maturity of the option. The path average and option payoff are then computed accordingly.

For the Asian option example, we also use the antithetic variance reduction technique. The antithetic simulation effectively increases the sample size by a factor of 2 . This factor should be taken into consideration if one intends to compare the simulation results with and without the antithetic sample. We are only interested in comparing the antithetic Monte Carlo simulation with and without the EMS correction. The antithetic simulation with the EMS can be easily performed by applying the EMS correction to the antithetic sample. The results for Asian options are reported in Table 3.

For Asian options, the patterns are similar to those for European options. The decrease in Monte Carlo errors due to the use of the EMS is much larger for in-the-money short-maturity options with a ratio of approximately 65. For Asian options, the use of the antithetic variable technique produces large decreases in standard deviations. With the EMS correction added onto the antithetic variable simulation, the additional improvement is clear as indicated by the ratios of standard deviations reported in the last row of either panel.

\subsection{The GARCH option pricing framework}

In the GARCH option pricing framework of Duan (1995), the asset price has a form analogous to equation (1) where the integrals are replaced by summations and the Brownian motion by the standard normal random variable. In this section, we use the GARCH(1,1)-(in mean) model to describe the daily asset return dynamic. According to Duan (1995), the dynamic under the locally risk-neutralized probability measure $Q$ is

$$
\begin{aligned}
\ln \frac{S_{t+1}}{S_{t}} & =r-\frac{1}{2} \sigma_{t+1}^{2}+\sigma_{t+1} \varepsilon_{t+1} \\
\sigma_{t+1}^{2} & =\beta_{0}+\beta_{1} \sigma_{t}^{2}+\beta_{2} \sigma_{t}^{2}\left(\varepsilon_{t}-\lambda\right)^{2} \\
\varepsilon_{t+1} \mid F_{t} & \stackrel{Q}{\sim} N(0,1)
\end{aligned}
$$

where $\beta_{0}, \beta_{1}, \beta_{2}$ are the $\operatorname{GARCH}(1,1)$ parameters, and $\lambda$ is the unit risk premium (per unit of standard deviation) parameter that defines the conditional mean equation of the GARCH(1,1)-(in mean) dynamic under the physical probability measure. By Duan (1995), the stationary variance of the daily asset return under the locally risk-neutralized probability measure $Q$ is $\beta_{0}\left[1-\beta_{1}-\right.$ $\left.\beta_{2}\left(1+\lambda^{2}\right)\right]^{-1}$, which is higher than $\beta_{0}\left(1-\beta_{1}-\beta_{2}\right)^{-1}$, the stationary variance under the physical probability measure.

In our numerical study, we set the initial conditional variance at the stationary level under the physical probability measure, i.e., $\sigma_{1}^{2}=\beta_{0}\left(1-\beta_{1}-\beta_{2}\right)^{-1}$. The crude Monte Carlo simulation is conducted according to the GARCH dynamic under $Q$ described above. The EMS is conducted 
by applying the EMS correction described in (9) to the simulated sample paths. For European options, we use their Black-Scholes counterparts in the control-variate Monte Carlo simulation. Following the practice in Duan (1995), the Black-Scholes price is computed using the stationary variance $\beta_{0}\left(1-\beta_{1}-\beta_{2}\right)^{-1}$ in the Black-Scholes closed-form formula. The results for European call options are presented in Table 4 . The error reduction due to the EMS is roughly the same as those under the Black-Scholes framework reported in Table 2. The use of control variate simulation reduces simulation error substantially. If one uses the EMS in conjunction with the control variate simulation further improves the simulation efficiency in a significant way. The improvement is insensitive to the number of sample paths, either 1000 or 10000, as indicated by the numbers in the two panels. As to the moneyness positions, the efficiency gain is most pronounced for in-the-money options. For out-of-the-money options, the efficiency gain increases as the maturity increases.

For Asian options, we use the contract specification described in the previous subsection. To conduct the control variate simulation, we have available the closed-form formula for geometric average options developed by Ritchken et al (1993). ${ }^{7}$ The results in Table 5 again clearly show the improvement due to the EMS. The patterns are the same as the ones for European options reported in Table 4.

\section{Conclusion}

Asset prices are typically modeled as exponential (semi-)martingales. The prices of its derivative contracts are often complex functionals that sometimes require the use of Monte Carlo simulation to compute their values. Although arbitrary degree of accuracy can be obtained by simulation, it often requires too many Monte Carlo repetitions. The Monte Carlo error can also cause the price estimate to violate rational option pricing bounds which makes these price estimates nonsensible. We propose a simple modification to the standard Monte Carlo simulation procedure. This modification is referred to as the empirical martingale simulation (EMS) because it imposes upon the simulated sample a martingale property. The EMS ensures that the price estimate by simulation satisfies rational option pricing bounds. Since the EMS reproduces a key feature of the theoretical model in simulation, it yields a substantial reduction in Monte Carlo errors. The EMS is applied to European and Asian call options under the Black-Scholes and GARCH frameworks to study the effect of path-dependency in payoffs and/or asset price dynamics. Substantial error reduction is obtained for all contracts under the two modeling approaches. The error reduction is particularly pronounced for in- and at-the-money options. The efficiency gain due to the EMS appears to be a typical phenomenon.

The benefit of using the EMS goes beyond Monte Carlo error reduction. The Black-Scholes formula is often used to compute implied volatility which is a means of comparing more complex option pricing models for the options with different strike prices and maturities. For example, one may want to study the validity of a stochastic volatility option pricing model by comparing

\footnotetext{
${ }^{7}$ We use the formula by Ritchken et al (1993) as the control because the Asian option studied here are written on the arithmetic average of discretely-sampled asset prices. This practice is similar to that of Kemna and Vorst (1990) except that our use of the formula by Ritchken et al avoids the bias associated with the use of a formula that is based on the geometric average of continuous prices.
} 
the implied volatilities computed from the market prices of exchange-traded options and their corresponding model prices. In order to compute the implied volatility, the option price estimate must satisfy rational option pricing bounds. To our knowledge, the EMS is the only Monte Carlo simulation technique that can ensure the satisfaction of rational option pricing bounds.

\section{Appendix}

\section{Proof of Proposition 1:}

Consider the $i$ th simulated sample path, $\left[\hat{S}_{i}\left(t_{1}\right), \cdots, \hat{S}_{i}\left(t_{m}\right)\right]$. The difference between $\hat{S}_{i}\left(t_{j}\right)$ and $S_{i}^{*}\left(t_{j}, n\right)$ is by a factor in the order of $S_{\mathbf{0}} / \hat{S}_{\mathbf{0}}\left(t_{j}, n\right)$. The strong law of large numbers assumption ensures that $\left[S_{i}^{*}\left(t_{1}, n\right), \cdots, S_{i}^{*}\left(t_{m}, n\right)\right]$ and $\left[\hat{S}_{i}\left(t_{1}\right), \cdots, \hat{S}_{i}\left(t_{m}\right)\right]$ can be made arbitrarily close, almost surely, for a large enough $n$. With the uniform continuity of $f(\cdot)$, we have the following result. For any $\varepsilon>0$, there exist $\delta>0$ and a large $N$ such that for any $n \geq N, \mid\left[S_{i}^{*}\left(t_{1}, n\right), \cdots, S_{i}^{*}\left(t_{m}, n\right)\right]-$ $\left[\hat{S}_{i}\left(t_{1}\right), \cdots, \hat{S}_{i}\left(t_{m}\right)\right] \mid<\delta$ almost surely, and $\left|f\left[S_{i}^{*}\left(t_{1}, n\right), \cdots, S_{i}^{*}\left(t_{m}, n\right)\right]-f\left[\hat{S}_{i}\left(t_{1}\right), \cdots, \hat{S}_{i}\left(t_{m}\right)\right]\right|<\varepsilon$ almost surely. The uniform continuity assumption also ensures that $\varepsilon, \delta$ and $N$ are independent of $\left[\hat{S}_{i}\left(t_{1}\right), \cdots, \hat{S}_{i}\left(t_{m}\right)\right]$. Setting $\varepsilon$ arbitrarily small yields the desired result.

\section{Proof of Proposition 2:}

Consider again the $i$ th simulated sample path, $\left[\hat{S}_{i}\left(t_{1}\right), \cdots, \hat{S}_{i}\left(t_{m}\right)\right]$. Since $S\left(t_{j}\right)$ has a continuous distribution for any $t_{j}$, this sample path must land, almost surely, in one of the subsets in the finite collection used to define the generic uniform continuity. Let this subset be denoted by $A$. We follow the same argument used in the proof for Proposition 1 to conclude the following: for any $\varepsilon_{A}>0$, there exist $\delta_{A}>0$ and a large $N_{A}$ such that for any $n \geq N_{A}, \mid\left[S_{i}^{*}\left(t_{1}, n\right), \cdots, S_{i}^{*}\left(t_{m}, n\right)\right]-\left[\hat{S}_{i}\left(t_{1}\right), \cdots\right.$ $\left.\cdot, \hat{S}_{i}\left(t_{m}\right)\right] \mid<\delta_{A}$ almost surely, and $\left|f\left[S_{i}^{*}\left(t_{1}, n\right), \cdots, S_{i}^{*}\left(t_{m}, n\right)\right]-f\left[\hat{S}_{i}\left(t_{1}\right), \cdots, \hat{S}_{i}\left(t_{m}\right)\right]\right|<\varepsilon_{A}$ almost surely. Since the collection of subsets is finite, the maxima for $\varepsilon_{A}, \delta_{A}$ and $N_{A}$ over this collection exist. Denote these maxima by $\varepsilon_{\max }, \delta_{\max }$ and $N_{\max }$. Replacing $\varepsilon_{A}, \delta_{A}$ and $N_{A}$ by $\varepsilon_{\max }$, $\delta_{\max }$ and $N_{\max }$ and then setting $\varepsilon_{\max }$ arbitrarily small yield the desired result. $\square$

\section{References}

[1] Barraquand, J., 1994, Numerical Valuation of High Dimensional Multivariate European Securities, Working paper, Digital Equipment Corporation (France), forthcoming in Management Science.

[2] Black, F. and M. Scholes, 1973, The Pricing of Options and Corporate Liabilities, Journal of Political Economics 81, 637-659.

[3] Boyle, P., 1977, Options: A Monte Carlo Approach, Journal of Financial Economics 4, 323338.

[4] Boyle, P., M. Broadie and P. Glasserman, 1995, Monte Carlo Methods for Security Pricing, Working paper, University of Waterloo, forthcoming in Journal of Economic Dynamics and Control. 
[5] Cox, J. and S. Ross, 1976, The Valuation of Options for Alternative Stochastic Processes, Journal of Financial Economics 3, 145-166.

[6] Duan, J., 1995, The GARCH Option Pricing Model, Mathematical Finance 5, 13-32.

[7] Harrison, J. and D. Kreps, 1979, Martingales and Arbitrage in Multiperiod Securities Markets, Journal of Economic Theory 20, 381-408.

[8] Harrison, J. and S. Pliska, 1981, Martingales and Stochastic Integrals in the Theory of Continuous Trading, Stochastic Processes and their Applications 11, 215-260.

[9] Hull, J. and A. White, 1987, The Pricing of Options on Assets with Stochastic Volatility, Journal of Finance 42, 281-299.

[10] Kemna, A. and A. Vorst, 1990, A Pricing Method for Options Based on Average Asset Values, Journal of Banking and Finance 14, 113-129.

[11] Lucas, R., 1978, Asset Prices in an Exchange Economy, Econometrica 46, 1429-1445.

[12] Merton, R., 1973, Theory of Rational Option Pricing, Bell Journal of Economics and Management Science 4, 141-183.

[13] Ritchken, P., L. Sankarasubramanian and A. Vijh, 1993, The Valuation of Path Dependent Contracts on the Average, Management Science 39, 1202-1213. 
Table 1

European call options in the Black and Scholes framework. Percentage of bound violations in a crude Monte Carlo simulation experiment with 1000 repetitions.

\begin{tabular}{|c|c|c|c|c|c|c|}
\hline \multirow[b]{2}{*}{$S_{0} / K$} & \multicolumn{3}{|c|}{1000 sample paths } & \multicolumn{3}{|c|}{10,000 sample paths } \\
\hline & $t=1$ month & $t=3$ months & $t=9$ months & $t=1$ month & $t=3$ months & $t=9$ months \\
\hline 1.50 & $51 \%$ & $51 \%$ & $51 \%$ & $48 \%$ & $48 \%$ & $46 \%$ \\
\hline 1.40 & 52 & 51 & 48 & 50 & 50 & 41 \\
\hline 1.30 & 49 & 49 & 38 & 52 & 50 & 22 \\
\hline 1.20 & 51 & 43 & 18 & 50 & 28 & 0 \\
\hline 1.10 & 34 & 3 & 0 & 8 & 0 & 0 \\
\hline 1.00 & 0 & 0 & 0 & 0 & 0 & 0 \\
\hline 0.90 & 0 & 0 & $\mathbf{0}$ & $\mathbf{0}$ & $\mathbf{0}$ & $\mathbf{0}$ \\
\hline 0.80 & 92 & $\mathbf{0}$ & $\mathbf{0}$ & 47 & $\mathbf{0}$ & 0 \\
\hline 0.70 & 100 & 70 & 0 & 100 & 3 & 0 \\
\hline 0.60 & 100 & 100 & 1 & 100 & 100 & 0 \\
\hline 0.50 & 100 & 100 & 89 & 100 & 100 & 33 \\
\hline
\end{tabular}

Parameters: $S_{0}=100, r=0.10$ (annualized) and $\sigma=0.20$ (annualized). 
Table 2

European call options in the Black and Scholes framework.

\begin{tabular}{|c|c|c|c|c|c|c|c|c|c|}
\hline \multirow[b]{2}{*}{$S_{0} / K$} & \multicolumn{3}{|c|}{ Maturity $=1$ month } & \multicolumn{3}{|c|}{$\begin{array}{l}1000 \text { sample paths } \\
\text { Maturity }=3 \text { months }\end{array}$} & \multicolumn{3}{|c|}{ Maturity $=9$ months } \\
\hline & 1.10 & 1.00 & 0.90 & 1.10 & 1.00 & 0.90 & 1.10 & 1.00 & 0.90 \\
\hline Theoretical & 9.9117 & 2.7104 & 0.1116 & 11.8209 & 5.2498 & 1.2147 & 16.9270 & 10.7748 & 5.4842 \\
\hline Crude & & & & & & & & & \\
\hline $\begin{array}{l}\text { mean } \\
\text { std. }\end{array}$ & $\begin{array}{c}9.9110 \\
(0.1745)\end{array}$ & $\begin{array}{c}2.7101 \\
(0.1202)\end{array}$ & $\begin{array}{c}0.1124 \\
(0.0226)\end{array}$ & $\begin{array}{l}11.8214 \\
(0.2861)\end{array}$ & $\begin{array}{c}5.2496 \\
(0.2232)\end{array}$ & $\begin{array}{c}1.2222 \\
(\mathbf{0 . 1 0 8 0})\end{array}$ & $\begin{array}{c}16.9289 \\
(0.4833)\end{array}$ & $\begin{array}{l}10.7751 \\
(0.4288)\end{array}$ & $\begin{array}{c}5.5070 \\
(0.3179)\end{array}$ \\
\hline EMS & & & & & & & & & \\
\hline $\begin{array}{l}\text { mean } \\
\text { std. }\end{array}$ & $\begin{array}{c}9.9119 \\
(0.0154)\end{array}$ & $\begin{array}{c}2.7106 \\
(0.0542)\end{array}$ & $\begin{array}{c}0.1116 \\
(0.0209)\end{array}$ & $\begin{array}{l}11.8221 \\
(\mathbf{0 . 0 4 9 3 )}\end{array}$ & $\begin{array}{c}5.2506 \\
(0.0909)\end{array}$ & $\begin{array}{c}1.2162 \\
(\mathbf{0 . 0 7 9 9 )}\end{array}$ & $\begin{array}{l}16.9291 \\
(0.0970)\end{array}$ & $\begin{array}{l}10.7776 \\
(0.1440)\end{array}$ & $\begin{array}{c}5.4873 \\
(0.1724)\end{array}$ \\
\hline $\begin{array}{l}\text { Ratio of std. } \\
\text { Crude/EMS }\end{array}$ & 11.3008 & 2.2176 & 1.0789 & 5.8051 & 2.4553 & 1.3514 & 4.9812 & 2.9785 & 1.8440 \\
\hline
\end{tabular}

\begin{tabular}{|c|c|c|c|c|c|c|c|c|c|}
\hline \multirow[b]{2}{*}{$S_{0} / K$} & \multicolumn{9}{|c|}{10,000 sample paths } \\
\hline & 1.10 & 1.00 & 0.90 & 1.10 & 1.00 & 0.90 & 1.10 & 1.00 & 0.90 \\
\hline Theoretical & 9.9117 & 2.7104 & 0.1116 & 11.8209 & 5.2498 & 1.2147 & 16.9270 & 10.7748 & 5.4842 \\
\hline Crude & & & & & & & & & \\
\hline $\begin{array}{l}\text { mean } \\
\text { std. }\end{array}$ & $\begin{array}{c}9.9121 \\
(0.0553)\end{array}$ & $\begin{array}{c}2.7098 \\
(0.0360)\end{array}$ & $\begin{array}{c}0.1114 \\
(0.0070)\end{array}$ & $\begin{array}{l}11.8223 \\
(0.0908)\end{array}$ & $\begin{array}{c}5.2491 \\
(0.0669)\end{array}$ & $\begin{array}{c}1.2149 \\
(0.0328)\end{array}$ & $\begin{array}{l}16.9301 \\
(0.1537)\end{array}$ & $\begin{array}{l}10.7741 \\
(0.1290)\end{array}$ & $\begin{array}{c}5.4845 \\
(0.0956)\end{array}$ \\
\hline EMS & & & & & & & & & \\
\hline $\begin{array}{l}\text { mean } \\
\text { std. }\end{array}$ & $\begin{array}{c}9.9120 \\
(0.0050)\end{array}$ & $\begin{array}{c}2.7096 \\
(0.0164)\end{array}$ & $\begin{array}{c}0.1113 \\
(0.0065)\end{array}$ & $\begin{array}{l}11.8219 \\
(0.0158)\end{array}$ & $\begin{array}{c}5.2486 \\
(0.0277)\end{array}$ & $\begin{array}{c}1.2146 \\
(0.0243)\end{array}$ & $\begin{array}{l}16.9290 \\
(0.0312)\end{array}$ & $\begin{array}{l}10.7735 \\
(0.0442)\end{array}$ & $\begin{array}{c}5.4836 \\
(0.0510)\end{array}$ \\
\hline $\begin{array}{l}\text { Ratio of std. } \\
\text { Crude/EMS }\end{array}$ & 11.0557 & 2.1987 & 1.0754 & 5.7363 & 2.4164 & 1.3529 & 4.9317 & 2.9190 & 1.8760 \\
\hline
\end{tabular}

Crude: Crude Monte Carlo simulation.

EMS: Empirical martingale simulation.

Parameters: $S_{0}=100, r=0.10$ (annualized) and $\sigma=0.20$ (annualized).

All results are based on a 1000 Monte Carlo experiment. 
Table 3

Asian call options in the Black and Scholes framework.

\begin{tabular}{|c|c|c|c|c|c|c|c|c|c|}
\hline \multirow[b]{2}{*}{$S_{0} / K$} & \multicolumn{6}{|c|}{$\begin{array}{l}1000 \text { sample paths } \\
\text { Maturity }=3 \text { months }\end{array}$} & \multicolumn{3}{|c|}{ Maturity $=9$ months } \\
\hline & 1.10 & 1.00 & 0.90 & 1.10 & 1.00 & 0.90 & 1.10 & 1.00 & 0.90 \\
\hline $\begin{array}{l}\text { Crude } \\
\text { mean } \\
\text { std. }\end{array}$ & $\begin{array}{c}9.4420 \\
(0.1027)\end{array}$ & $\begin{array}{c}1.5722 \\
(0.0676)\end{array}$ & $\begin{array}{c}0.0017 \\
(0.0019)\end{array}$ & $\begin{array}{l}10.1644 \\
(0.1727)\end{array}$ & $\begin{array}{c}2.9432 \\
(0.1227)\end{array}$ & $\begin{array}{c}0.1444 \\
(0.0264)\end{array}$ & $\begin{array}{l}12.3611 \\
(0.2886)\end{array}$ & $\begin{array}{c}5.8242 \\
(0.2268)\end{array}$ & $\begin{array}{c}1.5106 \\
(0.1186)\end{array}$ \\
\hline $\begin{array}{l}\text { EMS } \\
\text { mean } \\
\text { std. }\end{array}$ & $\begin{array}{c}9.4403 \\
(0.0015)\end{array}$ & $\begin{array}{c}1.5687 \\
(0.0325)\end{array}$ & $\begin{array}{c}0.0017 \\
(0.0019)\end{array}$ & $\begin{array}{l}10.1577 \\
(0.0134)\end{array}$ & $\begin{array}{c}2.9362 \\
(0.0527)\end{array}$ & $\begin{array}{c}0.1435 \\
(0.0237)\end{array}$ & $\begin{array}{l}12.3495 \\
(\mathbf{0 . 0 4 1 3 )}\end{array}$ & $\begin{array}{c}5.8093 \\
(0.0858)\end{array}$ & $\begin{array}{c}1.5051 \\
(0.0809)\end{array}$ \\
\hline $\begin{array}{l}\text { mean } \\
\text { std. } \\
\text { EMS-AT }\end{array}$ & $\begin{array}{c}9.4401 \\
(0.0036)\end{array}$ & $\begin{array}{c}1.5696 \\
(0.0341)\end{array}$ & $\begin{array}{c}0.0016 \\
(0.0014)\end{array}$ & $\begin{array}{l}10.1575 \\
(0.0181)\end{array}$ & $\begin{array}{c}2.9373 \\
(0.0573)\end{array}$ & $\begin{array}{c}0.1445 \\
(0.0187)\end{array}$ & $\begin{array}{l}12.3503 \\
(0.0570)\end{array}$ & $\begin{array}{c}5.8121 \\
(0.1008)\end{array}$ & $\begin{array}{c}1.5069 \\
(0.0782)\end{array}$ \\
\hline $\begin{array}{l}\text { mean } \\
\text { std. } \\
\text { Ratio of std. }\end{array}$ & $\begin{array}{c}9.4403 \\
(0.0011)\end{array}$ & $\begin{array}{c}1.5688 \\
(0.0324)\end{array}$ & $\begin{array}{c}0.0016 \\
(0.0014)\end{array}$ & $\begin{array}{l}10.1579 \\
(0.0105)\end{array}$ & $\begin{array}{c}2.9358 \\
(0.0522)\end{array}$ & $\begin{array}{c}0.1442 \\
(0.0182)\end{array}$ & $\begin{array}{l}12.3504 \\
(\mathbf{0 . 0 3 3 9 )}\end{array}$ & $\begin{array}{c}5.8092 \\
(0.0837)\end{array}$ & $\begin{array}{c}1.5053 \\
(0.0712)\end{array}$ \\
\hline $\begin{array}{l}\text { Crude/EMS } \\
\text { AT/EMS-AT }\end{array}$ & $\begin{array}{c}66.6979 \\
3.3457\end{array}$ & $\begin{array}{l}2.0795 \\
1.0526\end{array}$ & $\begin{array}{l}1.0037 \\
1.0060\end{array}$ & $\begin{array}{c}12.8909 \\
1.7298\end{array}$ & $\begin{array}{l}2.3264 \\
1.0976\end{array}$ & $\begin{array}{l}1.1107 \\
1.0247\end{array}$ & $\begin{array}{l}6.9917 \\
1.6831\end{array}$ & $\begin{array}{l}2.6427 \\
1.2041\end{array}$ & $\begin{array}{l}1.4661 \\
1.0971\end{array}$ \\
\hline \multirow[b]{2}{*}{$S_{0} / K$} & \multicolumn{3}{|c|}{ Maturity $=1$ month } & \multicolumn{3}{|c|}{$\begin{array}{l}\text { 10,000 sample paths } \\
\text { Maturity }=3 \text { months }\end{array}$} & \multicolumn{3}{|c|}{ Maturity $=9$ months } \\
\hline & 1.10 & 1.00 & 0.90 & 1.10 & 1.00 & 0.90 & 1.10 & 1.00 & 0.90 \\
\hline $\begin{array}{l}\text { Crude } \\
\text { mean } \\
\text { std. }\end{array}$ & $\begin{array}{c}9.4415 \\
(0.0313)\end{array}$ & $\begin{array}{c}1.5682 \\
(0.0222)\end{array}$ & $\begin{array}{c}0.0016 \\
(0.0006)\end{array}$ & $\begin{array}{l}10.1590 \\
(0.0542)\end{array}$ & $\begin{array}{c}2.9337 \\
(0.0378)\end{array}$ & $\begin{array}{c}0.1450 \\
(0.0084)\end{array}$ & $\begin{array}{l}12.3520 \\
(0.0879)\end{array}$ & $\begin{array}{c}5.8054 \\
(0.0670)\end{array}$ & $\begin{array}{c}1.5086 \\
(0.0381)\end{array}$ \\
\hline $\begin{array}{l}\text { EMS } \\
\text { mean } \\
\text { std. }\end{array}$ & $\begin{array}{c}9.4402 \\
(0.0005)\end{array}$ & $\begin{array}{c}1.5681 \\
(0.0102)\end{array}$ & $\begin{array}{c}0.0016 \\
(0.0006)\end{array}$ & $\begin{array}{l}10.1582 \\
(0.0044)\end{array}$ & $\begin{array}{c}2.9331 \\
(0.0167)\end{array}$ & $\begin{array}{c}0.1450 \\
(0.0076)\end{array}$ & $\begin{array}{l}12.3522 \\
(\mathbf{0 . 0 1 3 3 )}\end{array}$ & $\begin{array}{c}5.8047 \\
(0.0265)\end{array}$ & $\begin{array}{c}1.5086 \\
(0.0266)\end{array}$ \\
\hline $\begin{array}{l}\text { AT } \\
\text { mean } \\
\text { std. }\end{array}$ & $\begin{array}{c}9.4403 \\
(0.0012)\end{array}$ & $\begin{array}{c}1.5681 \\
(0.0107)\end{array}$ & $\begin{array}{c}0.0016 \\
(0.0004)\end{array}$ & $\begin{array}{l}10.1583 \\
(0.0058)\end{array}$ & $\begin{array}{c}2.9330 \\
(0.0181)\end{array}$ & $\begin{array}{c}0.1450 \\
(0.0059)\end{array}$ & $\begin{array}{l}12.3520 \\
(0.0185)\end{array}$ & $\begin{array}{c}5.8049 \\
(0.0314)\end{array}$ & $\begin{array}{c}1.5089 \\
(0.0251)\end{array}$ \\
\hline $\begin{array}{l}\text { EMS-AT } \\
\text { mean } \\
\text { std. }\end{array}$ & $\begin{array}{c}9.4403 \\
(0.0003)\end{array}$ & $\begin{array}{c}1.5681 \\
(0.0102)\end{array}$ & $\begin{array}{c}0.0016 \\
(0.0004)\end{array}$ & $\begin{array}{l}10.1583 \\
(0.0033)\end{array}$ & $\begin{array}{c}2.9330 \\
(0.0165)\end{array}$ & $\begin{array}{c}0.1449 \\
(0.0058)\end{array}$ & $\begin{array}{l}12.3521 \\
(\mathbf{0 . 0 1 1 0})\end{array}$ & $\begin{array}{c}5.8048 \\
(0.0261)\end{array}$ & $\begin{array}{c}1.5087 \\
(0.0229)\end{array}$ \\
\hline Crude/EMS & 65.7908 & 2.1663 & 1.0018 & 12.2413 & 2.2651 & 1.1044 & 6.5856 & 2.5300 & 1.4324 \\
\hline AT/EMS-AT & 3.4158 & 1.0511 & 1.0013 & 1.7526 & 1.0957 & 1.0262 & 1.6805 & 1.2023 & 1.0960 \\
\hline
\end{tabular}

Crude: Crude Monte Carlo simulation.

EMS: Empirical martingale simulation.

AT: Antithetic simulation.

EMS-AT: Antithetic empirical martingale simulation.

Parameters: $S_{0}=100, r=0.10$ (annualized) and $\sigma=\mathbf{0 . 2 0}$ (annualized).

All results are based on a 1000 Monte Carlo experiment. 
Table 4

European call options in the GARCH framework.

\begin{tabular}{|c|c|c|c|c|c|c|c|c|c|}
\hline \multirow[b]{2}{*}{$S_{0} / K$} & \multicolumn{9}{|c|}{1000 sample paths } \\
\hline & 1.10 & 1.00 & 0.90 & 1.10 & 1.00 & 0.90 & 1.10 & 1.00 & 0.90 \\
\hline $\begin{array}{l}\text { Crude } \\
\text { mean } \\
\text { std. }\end{array}$ & $\begin{array}{c}9.9315 \\
(0.1613)\end{array}$ & $\begin{array}{c}2.5441 \\
(0.1138)\end{array}$ & $\begin{array}{c}0.1158 \\
(0.0285)\end{array}$ & $\begin{array}{l}11.7621 \\
(0.2702)\end{array}$ & $\begin{array}{c}5.0233 \\
(0.2123)\end{array}$ & $\begin{array}{c}1.0682 \\
(0.1060)\end{array}$ & $\begin{array}{c}16.7665 \\
(0.4803)\end{array}$ & $\begin{array}{l}10.4872 \\
(0.4127)\end{array}$ & $\begin{array}{c}5.1266 \\
(0.3043)\end{array}$ \\
\hline $\begin{array}{l}\text { EMS } \\
\text { mean } \\
\text { std. }\end{array}$ & $\begin{array}{c}9.9216 \\
(0.0207)\end{array}$ & $\begin{array}{c}2.5381 \\
(0.0562)\end{array}$ & $\begin{array}{c}0.1153 \\
(0.0265)\end{array}$ & $\begin{array}{l}11.7548 \\
(0.0496)\end{array}$ & $\begin{array}{c}5.0169 \\
(0.0886)\end{array}$ & $\begin{array}{c}1.0633 \\
(0.0775)\end{array}$ & $\begin{array}{c}16.7580 \\
(0.0942)\end{array}$ & $\begin{array}{c}10.4724 \\
(0.1411)\end{array}$ & $\begin{array}{c}5.1183 \\
(0.1628)\end{array}$ \\
\hline $\begin{array}{l}\text { CV } \\
\text { mean } \\
\text { std. }\end{array}$ & $\begin{array}{c}9.9219 \\
(0.0431)\end{array}$ & $\begin{array}{c}2.5369 \\
(0.0349)\end{array}$ & $\begin{array}{c}0.1159 \\
(0.0182)\end{array}$ & $\begin{array}{l}11.7542 \\
(0.0818)\end{array}$ & $\begin{array}{c}5.0091 \\
(0.0677)\end{array}$ & $\begin{array}{c}1.0655 \\
(0.0496)\end{array}$ & $\begin{array}{l}16.7486 \\
(0.1446)\end{array}$ & $\begin{array}{l}10.4620 \\
(0.1314)\end{array}$ & $\begin{array}{c}5.1216 \\
(0.1117)\end{array}$ \\
\hline $\begin{array}{l}\text { EMS-CV } \\
\text { mean } \\
\text { std. }\end{array}$ & $\begin{array}{c}9.9221 \\
(0.0140)\end{array}$ & $\begin{array}{c}2.5363 \\
(0.0218)\end{array}$ & $\begin{array}{c}0.1159 \\
(0.0174)\end{array}$ & $\begin{array}{l}11.7581 \\
(0.0298)\end{array}$ & $\begin{array}{c}5.0134 \\
(0.0392)\end{array}$ & $\begin{array}{c}1.0657 \\
(0.0413)\end{array}$ & $\begin{array}{c}16.7578 \\
(0.0464)\end{array}$ & $\begin{array}{l}10.4665 \\
(0.0633)\end{array}$ & $\begin{array}{c}5.1219 \\
(0.0743)\end{array}$ \\
\hline $\begin{array}{l}\text { Ratio of std. } \\
\text { Crude/EMS } \\
\text { CV/EMS-CV }\end{array}$ & $\begin{array}{l}7.7764 \\
3.0688\end{array}$ & $\begin{array}{l}2.0238 \\
1.6010\end{array}$ & $\begin{array}{l}1.0763 \\
1.0490\end{array}$ & $\begin{array}{l}5.4493 \\
2.7497\end{array}$ & $\begin{array}{l}2.3959 \\
1.7277\end{array}$ & $\begin{array}{l}1.3675 \\
1.2005\end{array}$ & $\begin{array}{l}5.0964 \\
3.1206\end{array}$ & $\begin{array}{l}2.9254 \\
2.0741\end{array}$ & $\begin{array}{l}1.8691 \\
1.5044\end{array}$ \\
\hline
\end{tabular}

\begin{tabular}{|c|c|c|c|c|c|c|c|c|c|}
\hline \multirow[b]{2}{*}{$S_{0} / K$} & \multicolumn{9}{|c|}{10,000 sample paths } \\
\hline & 1.10 & 1.00 & 0.90 & 1.10 & 1.00 & 0.90 & 1.10 & 1.00 & 0.90 \\
\hline Crude & & & & & & & & & \\
\hline $\begin{array}{l}\text { mean } \\
\text { std. }\end{array}$ & $\begin{array}{c}9.9231 \\
(0.0495)\end{array}$ & $\begin{array}{c}2.5364 \\
(\mathbf{0 . 0 3 6 0 )}\end{array}$ & $\begin{array}{c}0.1164 \\
(0.0094)\end{array}$ & $\begin{array}{l}11.7578 \\
(0.0861)\end{array}$ & $\begin{array}{c}5.0104 \\
(0.0634)\end{array}$ & $\begin{array}{c}1.0619 \\
(0.0335)\end{array}$ & $\begin{array}{c}16.7528 \\
(0.1427)\end{array}$ & $\begin{array}{l}10.4640 \\
(0.1261)\end{array}$ & $\begin{array}{c}5.1197 \\
(0.0958)\end{array}$ \\
\hline EMS & & & & & & & & & \\
\hline $\begin{array}{l}\text { mean } \\
\text { std. }\end{array}$ & $\begin{array}{c}9.9217 \\
(0.0066)\end{array}$ & $\begin{array}{c}2.5361 \\
(0.0171)\end{array}$ & $\begin{array}{c}0.1164 \\
(0.0088)\end{array}$ & $\begin{array}{l}11.7568 \\
(0.0164)\end{array}$ & $\begin{array}{c}5.0107 \\
(0.0280)\end{array}$ & $\begin{array}{c}1.0622 \\
(0.0261)\end{array}$ & $\begin{array}{c}16.7566 \\
(0.0305)\end{array}$ & $\begin{array}{c}10.4639 \\
(0.0444)\end{array}$ & $\begin{array}{c}5.1191 \\
(0.0513)\end{array}$ \\
\hline CV & & & & & & & & & \\
\hline $\begin{array}{l}\text { mean } \\
\text { std. }\end{array}$ & $\begin{array}{c}9.9220 \\
(0.0133)\end{array}$ & $\begin{array}{c}2.5358 \\
(0.0108)\end{array}$ & $\begin{array}{c}0.1165 \\
(0.0061)\end{array}$ & $\begin{array}{c}11.7578 \\
(0.0249)\end{array}$ & $\begin{array}{c}5.0109 \\
(0.0220)\end{array}$ & $\begin{array}{c}1.0616 \\
(0.0159)\end{array}$ & $\begin{array}{l}16.7564 \\
(0.0456)\end{array}$ & $\begin{array}{c}10.4638 \\
(0.0415)\end{array}$ & $\begin{array}{c}5.1191 \\
(0.0341)\end{array}$ \\
\hline EMS-CV & & & & & & & & & \\
\hline $\begin{array}{l}\text { mean } \\
\text { std. }\end{array}$ & $\begin{array}{c}9.9218 \\
(0.0044)\end{array}$ & $\begin{array}{c}2.5360 \\
(0.0067)\end{array}$ & $\begin{array}{c}0.1165 \\
(0.0058)\end{array}$ & $\begin{array}{l}11.7575 \\
(0.0088)\end{array}$ & $\begin{array}{c}5.0117 \\
(0.0126)\end{array}$ & $\begin{array}{c}1.0618 \\
(0.0135)\end{array}$ & $\begin{array}{c}16.7570 \\
(0.0145)\end{array}$ & $\begin{array}{l}10.4647 \\
(0.0204)\end{array}$ & $\begin{array}{c}5.1200 \\
(0.0218)\end{array}$ \\
\hline Ratio of std. & & & & & & & & & \\
\hline Crude/EMS & 7.4960 & 2.1047 & 1.0702 & 5.2549 & 2.2655 & 1.2850 & 4.6835 & 2.8417 & 1.8648 \\
\hline CV/EMS-CV & 3.0347 & 1.6170 & 1.0388 & 2.8087 & 1.7387 & 1.1745 & 3.1437 & 2.0329 & 1.5620 \\
\hline
\end{tabular}

EMS: Empirical martingale simulation.

$\mathrm{CV}$ : Control variate simulation.

EMS-CV: Control variate empirical martingale simulation.

Parameters: $S_{0}=100, r=0.10$ (annualized), $\beta_{0}=0.00001, \beta_{1}=0.70, \beta_{2}=0.20$ and $\lambda=0.01$.

All results are based on a 1000 Monte Carlo experiment. 
Table 5

Asian call options in the GARCH framework.

\begin{tabular}{|c|c|c|c|c|c|c|c|c|c|}
\hline \multirow[b]{2}{*}{$S_{0} / K$} & \multicolumn{9}{|c|}{1000 sample paths } \\
\hline & 1.10 & 1.00 & 0.90 & 1.10 & 1.00 & 0.90 & 1.10 & 1.00 & 0.90 \\
\hline $\begin{array}{l}\text { Crude } \\
\text { mean } \\
\text { std. }\end{array}$ & $\begin{array}{c}9.4468 \\
(0.0980)\end{array}$ & $\begin{array}{c}1.4690 \\
(0.0653)\end{array}$ & $\begin{array}{c}0.0070 \\
(0.0062)\end{array}$ & $\begin{array}{l}10.1677 \\
(0.1627)\end{array}$ & $\begin{array}{c}2.7930 \\
(0.1190)\end{array}$ & $\begin{array}{c}0.1365 \\
(0.0298)\end{array}$ & $\begin{array}{c}12.3077 \\
(0.2722)\end{array}$ & $\begin{array}{c}5.6250 \\
(0.2210)\end{array}$ & $\begin{array}{c}1.3501 \\
(0.1139)\end{array}$ \\
\hline $\begin{array}{l}\text { EMS } \\
\text { mean } \\
\text { std. }\end{array}$ & $\begin{array}{c}9.4452 \\
(0.0049)\end{array}$ & $\begin{array}{c}1.4657 \\
(0.0335)\end{array}$ & $\begin{array}{c}0.0070 \\
(0.0061)\end{array}$ & $\begin{array}{l}10.1627 \\
(0.0174)\end{array}$ & $\begin{array}{c}2.7873 \\
(0.0523)\end{array}$ & $\begin{array}{c}0.1358 \\
(0.0272)\end{array}$ & $\begin{array}{c}12.3005 \\
(0.0406)\end{array}$ & $\begin{array}{c}5.6143 \\
(0.0836)\end{array}$ & $\begin{array}{c}1.3451 \\
(0.0797)\end{array}$ \\
\hline $\begin{array}{l}\text { CV } \\
\text { mean } \\
\text { std. } \\
\text { EMS-CV }\end{array}$ & $\begin{array}{c}9.4451 \\
(\mathbf{0 . 0 2 2 7})\end{array}$ & $\begin{array}{c}1.4649 \\
(0.0177)\end{array}$ & $\begin{array}{c}0.0070 \\
(0.0054)\end{array}$ & $\begin{array}{l}10.1619 \\
(0.0448)\end{array}$ & $\begin{array}{c}2.7841 \\
(\mathbf{0 . 0 3 6 0 )}\end{array}$ & $\begin{array}{c}0.1369 \\
(0.0182)\end{array}$ & $\begin{array}{c}12.2995 \\
(0.0812)\end{array}$ & $\begin{array}{c}5.6072 \\
(0.0683)\end{array}$ & $\begin{array}{c}1.3485 \\
(0.0498)\end{array}$ \\
\hline $\begin{array}{l}\text { mean } \\
\text { std. }\end{array}$ & $\begin{array}{c}9.4451 \\
(0.0043)\end{array}$ & $\begin{array}{c}1.4648 \\
(0.0115)\end{array}$ & $\begin{array}{c}0.0070 \\
(0.0053)\end{array}$ & $\begin{array}{l}10.1634 \\
(0.0121)\end{array}$ & $\begin{array}{c}2.7850 \\
(0.0217)\end{array}$ & $\begin{array}{c}0.1370 \\
(0.0173)\end{array}$ & $\begin{array}{c}12.3031 \\
(0.0245)\end{array}$ & $\begin{array}{c}5.6103 \\
(0.0353)\end{array}$ & $\begin{array}{c}1.3481 \\
(0.0398)\end{array}$ \\
\hline $\begin{array}{l}\text { Ratio of std. } \\
\text { Crude/EMS } \\
\text { CV/EMS-CV }\end{array}$ & $\begin{array}{c}19.9224 \\
5.2531\end{array}$ & $\begin{array}{l}1.9479 \\
1.5449\end{array}$ & & $\begin{array}{l}9.3353 \\
3.6931\end{array}$ & $\begin{array}{l}2.2760 \\
1.6585\end{array}$ & & & & $\begin{array}{l}1.4280 \\
1.2522\end{array}$ \\
\hline & Mat & $y=1$ & nth & $\begin{array}{l}10, \\
\text { Mat }\end{array}$ & $y=\mathbf{3}$ & $\begin{array}{l}\text { ths } \\
\text { ths }\end{array}$ & Mat & $y=9 n$ & ths \\
\hline$S_{0} / K$ & 1.10 & 1.00 & 0.90 & 1.10 & 1.00 & 0.90 & 1.10 & 1.00 & 0.90 \\
\hline $\begin{array}{l}\text { Crude } \\
\text { mean } \\
\text { std. }\end{array}$ & $\begin{array}{c}9.4464 \\
(0.0296)\end{array}$ & $\begin{array}{c}1.4645 \\
(0.0215)\end{array}$ & $\begin{array}{c}0.0071 \\
(0.0020)\end{array}$ & $\begin{array}{c}10.1638 \\
(0.0512)\end{array}$ & $\begin{array}{c}2.7838 \\
(0.0368)\end{array}$ & $\begin{array}{c}0.1369 \\
(0.0097)\end{array}$ & $\begin{array}{c}12.3020 \\
(\mathbf{0 . 0 8 4 2 )}\end{array}$ & $\begin{array}{c}5.6090 \\
(0.0650)\end{array}$ & $\begin{array}{c}1.3442 \\
(\mathbf{0 . 0 3 6 0 )}\end{array}$ \\
\hline $\begin{array}{l}\text { EMS } \\
\text { mean } \\
\text { std. }\end{array}$ & $\begin{array}{c}9.4450 \\
(0.0015)\end{array}$ & $\begin{array}{c}1.4646 \\
(0.0104)\end{array}$ & $\begin{array}{c}0.0071 \\
(0.0019)\end{array}$ & $\begin{array}{l}10.1628 \\
(0.0055)\end{array}$ & $\begin{array}{c}2.7835 \\
(0.0165)\end{array}$ & $\begin{array}{c}0.1369 \\
(0.0090)\end{array}$ & $\begin{array}{c}12.3022 \\
(\mathbf{0 . 0 1 3 3 )}\end{array}$ & $\begin{array}{c}5.6089 \\
(0.0260)\end{array}$ & $\begin{array}{c}1.3444 \\
(0.0261)\end{array}$ \\
\hline $\begin{array}{l}\text { CV } \\
\text { mean } \\
\text { std. }\end{array}$ & $\begin{array}{c}9.4452 \\
(\mathbf{0 . 0 0 7 0})\end{array}$ & $\begin{array}{c}1.4642 \\
(\mathbf{0 . 0 0 5 3 )}\end{array}$ & $\begin{array}{c}0.0071 \\
(0.0017)\end{array}$ & $\begin{array}{c}10.1633 \\
(0.0139)\end{array}$ & $\begin{array}{c}2.7839 \\
(0.0112)\end{array}$ & $\begin{array}{c}0.1368 \\
(0.0061)\end{array}$ & $\begin{array}{c}12.3023 \\
(0.0251)\end{array}$ & $\begin{array}{c}5.6086 \\
(0.0221)\end{array}$ & $\begin{array}{c}1.3441 \\
(0.0154)\end{array}$ \\
\hline $\begin{array}{l}\text { EMS-CV } \\
\text { mean } \\
\text { std. }\end{array}$ & $\begin{array}{c}9.4451 \\
(0.0014)\end{array}$ & $\begin{array}{c}1.4643 \\
(0.0035)\end{array}$ & $\begin{array}{c}0.0071 \\
(0.0017)\end{array}$ & $\begin{array}{l}10.1630 \\
(0.0039)\end{array}$ & $\begin{array}{c}2.7842 \\
(\mathbf{0 . 0 0 6 6 )}\end{array}$ & $\begin{array}{c}0.1368 \\
(0.0058)\end{array}$ & $\begin{array}{c}12.3023 \\
(0.0075)\end{array}$ & $\begin{array}{c}5.6091 \\
(0.0117)\end{array}$ & $\begin{array}{c}1.3444 \\
(\mathbf{0 . 0 1 2 4 )}\end{array}$ \\
\hline $\begin{array}{l}\text { Ratio of std. } \\
\text { Crude/EMS } \\
\text { CV/EMS-CV }\end{array}$ & $\begin{array}{c}19.3821 \\
5.1603\end{array}$ & $\begin{array}{l}2.0732 \\
1.5423\end{array}$ & $\begin{array}{l}1.0087 \\
1.0091\end{array}$ & $\begin{array}{l}9.2653 \\
3.6020\end{array}$ & $\begin{array}{l}2.2327 \\
1.7009\end{array}$ & $\begin{array}{l}1.0812 \\
1.0519\end{array}$ & $\begin{array}{l}6.3184 \\
3.3290\end{array}$ & $\begin{array}{l}2.4944 \\
1.8843\end{array}$ & $\begin{array}{l}1.3818 \\
1.2460\end{array}$ \\
\hline
\end{tabular}

EMS: Empirical martingale simulation.

$\mathrm{CV}$ : Control variate simulation.

EMS-CV: Control variate empirical martingale simulation.

Parameters: $S_{0}=100, r=0.10$ (annualized), $\beta_{0}=\mathbf{0 . 0 0 0 0 1 ,} \beta_{1}=\mathbf{0 . 7 0}, \beta_{2}=\mathbf{0 . 2 0}$ and $\lambda=0.01$.

All results are based on a 1000 Monte Carlo experiment. 


\section{Liste des publications au CIRANO}

\section{Cahiers CIRANO / CIRANO Papers (ISSN 1198-8169)}

94c-1 Faire ou faire faire : La perspective de l'économie des organisations / par Michel Patry

94c-2 Commercial Bankruptcy and Financial Reorganization in Canada / par Jocelyn Martel

94c-3 L'importance relative des gouvernements : causes, conséquences, et organisations alternatives / par Claude Montmarquette

95c-1 La réglementation incitative / par Marcel Boyer

95c-2 Anomalies de marché et sélection des titres au Canada / par Richard Guay, Jean-François L'Her et Jean-Marc Suret

\section{Série Scientifique / Scientific Series (ISSN 1198-8177)}

95s-28 Survol des contributions théoriques et empiriques liées au capital humain / par Daniel Parent

95s-29 Heterogeneous Expectations, Short Sales Relation and the Risk-Return Relationship / par Jean-François L'Her et Jean-Marc Suret

95s-30 L'impact de la réglementation en matière de santé et sécurité du travail sur le risque d'accident au Québec : de nouveaux résultats / par Paul Lanoie et David Stréliski

95s-31 Stochastic Volatility and Time Deformation: An Application to Trading Volume and Leverage Effects / par Eric Ghysels et Joanna Jasiak

95s-32 Market Time and Asset Price Movements Theory and Estimation / par Eric Ghysels, Christian Gouriéroux et Joanna Jasiak

95s-33 Real Investment Decisions Under Information Constraints / par Gérard Gaudet, Pierre Lasserre et Ngo Van Long

95s-34 Signaling in Financial Reorganization: Theory and Evidence from Canada / parJocelyn Martel

95s-35 Capacity Commitment Versus Flexibility: The Technological Choice Nexus in a Strategic Context / Marcel Boyer et Michel Moreaux

95s-36 Some Results on the Markov Equilibria of a class of Homogeneous Differential Games / Ngo Van Long et Koji Shimomura

95s-37 Dynamic Incentive Contracts with Uncorrelated Private Information and History Dependent Outcomes / Gérard Gaudet, Pierre Lasserre et Ngo Van Long

95s-38 Costs and Benefits of Preventing Worplace Accidents: The Case of Participatory Ergonomics / Paul Lanoie et Sophie Tavenas

95s-39 On the Dynamic Specification of International Asset Pricing Models / Maral kichian, René Garcia et Eric Ghysels

95s-40 Vertical Integration, Foreclosure and Profits in the Presence of Double Marginalisation / Gérard Gaudet et Ngo Van Long

95s-41 Testing the Option Value Theory of Irreversible Investment / Tarek M. Harchaoui et Pierre Lasserre

95s-42 Trading Patterns, Time Deformation and Stochastic Volatility in Foreign Exchange Markets / Eric Ghysels, Christian Gouriéroux et Joanna Jasiak

95s-43 Empirical Martingale Simulation for Asset Prices / Jin-Chuan Duan et Jean-Guy Simonato 